\title{
Sustainable Development Goals, Financial Inclusion, and Grain Security Efficiency
}

\author{
Shuaishuai Jia ${ }^{1}\left(\right.$, Yushan Qiu $^{2}$ and Cunyi Yang ${ }^{2, *} \mathbb{1}$ \\ 1 Guangzhou Institute of International Finance, Guangzhou University, Guangzhou 510405, China; \\ tongijia@gzhu.edu.cn \\ 2 School of Economics and Statistics, Guangzhou University, Guangzhou 510006, China; \\ 2112164126@e.gzhu.edu.cn \\ * Correspondence: 2112064077@e.gzhu.edu.cn
}

check for updates

Citation: Jia, S.; Qiu, Y.; Yang, C. Sustainable Development Goals, Financial Inclusion, and Grain Security Efficiency. Agronomy 2021, 11, 2542. https://doi.org/10.3390/ agronomy11122542

Academic Editors: Djamilia Skripnuk and Gulnara Romashkina

Received: 14 November 2021 Accepted: 13 December 2021 Published: 14 December 2021

Publisher's Note: MDPI stays neutral with regard to jurisdictional claims in published maps and institutional affiliations.

Copyright: (c) 2021 by the authors. Licensee MDPI, Basel, Switzerland. This article is an open access article distributed under the terms and conditions of the Creative Commons Attribution (CC BY) license (https:// creativecommons.org/licenses/by/ $4.0 /)$.

\begin{abstract}
The 17 sustainable development goals proposed in the 2030 sustainable development agenda are the shared vision of all humanity. The core of achieving the sustainable development goals is to ensure grain security. Although financial inclusion is not separately incorporated into the United Nations sustainable development goals, it is an essential basis for supporting all sustainable development goals. Financial inclusion plays a critical role in improving grain security efficiency to ensure sustainable grain security. According to the Financial Access Survey implemented by IMF, this study calculated the financial inclusion index and grain security efficiency of 121 countries from 2015 to 2019. Based on calculating the efficiency of grain security in production and distribution, this study used an econometric model to empirically examine the role of financial inclusion in improving grain security efficiency. The study found that financial inclusion can promote grain security efficiency from the two links of production and distribution. Still, the improvement of grain security efficiency by financial inclusion is mainly reflected in the distribution. Further, the study found that the advancement of financial inclusion promotes the efficiency of grain distribution through the effects of residents' income distribution, residents' income growth, and consumption capacity upgrading, which achieves the goal of ensuring grain security and promoting sustainable development.
\end{abstract}

Keywords: sustainable development goal; financial inclusion; grain security efficiency; grain production efficiency; grain distribution efficiency

\section{Introduction}

\subsection{Research Motivation}

In September 2015, the United Nations Development Summit demonstrated the vision of all countries to pursue win-win cooperation and realize common development, and adopted the 2030 sustainable development agenda. The agenda is an action plan for humanity, the earth, and prosperity. It puts forward 17 sustainable development goals (SDGs) and 169 specific goals, illustrating the scale and ambition of this new global agenda. The 17 SDGs of the 2030 Agenda for Sustainable Development have food at their very core. Sustainable agri-food systems are critical to achieving all dimensions of sustainable development [1].

The Food and Agriculture Organization of the United Nations proposed in 1983 that the goal of grain security is "to ensure that all people can buy and afford the basic food they need at any time". This goal contains three meanings: to ensure the production of sufficient food, maximize the stability of food supply, and ensure that all those who need food have access to food. Grain security is embodied in the common security of multiple links such as production, supply, and distribution. Fair grain distribution efficiency is the key to achieving grain security.

Financial inclusion refers to a process that ensures the ease of access, availability, and usage of the formal financial system for all members of an economy. It facilitates 
the efficient allocation of productive resources and thus can potentially reduce the cost of capital [2]. Although financial inclusion is not explicitly incorporated into the United Nations sustainable development goals, we believe it plays a core role in supporting the sustainable development goals and finance.

Generally speaking, low-income people in developing or developed countries are threatened by grain security, which may have obstacles in grain production, grain supply, or grain distribution. The improvement of financial inclusion can strengthen the guarantee of individual peasants' production capacity, and increase low-income people's income and purchasing power. Therefore, financial inclusion can play a beneficial supporting effect in improving grain production capacity, grain distribution efficiency, and grain security. The main aim of this study is to investigate the problem of financial inclusion promoting grain distribution efficiency and sustainable grain security based on transnational samples, and investigate the effect and mechanism of financial inclusion promoting grain distribution and ensuring grain security.

Figure 1 is the logical framework of this paper. The structure of this paper is as follows:

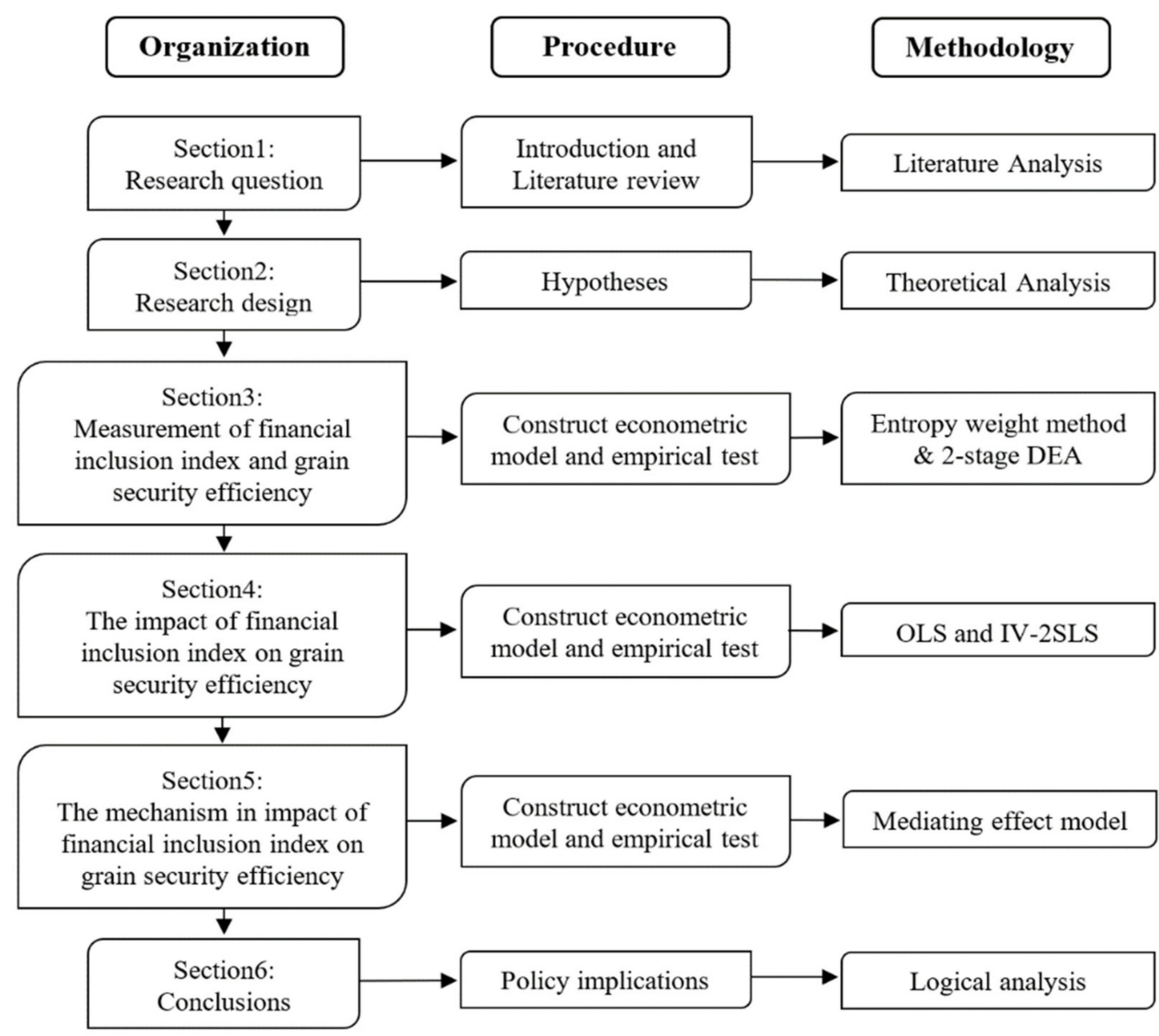

Figure 1. The logical framework of this paper.

The first section of this paper puts forward the core research issue by introducing empirical facts and the induction of existing literature. How does financial inclusion affect the efficiency of grain security from the perspective of sustainable development goals? Based on the analysis of the relationship between key variables, the second part puts forward the research hypothesis of this paper and introduces the empirical model and data sources. The third part uses the econometric model to measure the key variables. The fourth part empirically examines the impact of financial inclusion on grain security efficiency and its two-stage decomposition indicators, and conducts a Robustness Test. The fifth part empirically analyzes the impact mechanism of financial inclusion on grain distribution efficiency. The sixth part is the primary conclusion of the paper. 


\subsection{Literature Review and Contribution}

Financial development can provide financial support for economic development, and the market-oriented operation of financial institutions can optimize resource allocation and provide economic development efficiency. The main role of financial markets and institutions in the economy is to improve the efficiency of capital allocation, mobilize savings, guide more capital formation, manage risks, and promote transactions. A wellfunctioning financial system should promote economic growth and reduce poverty by improving information and transaction costs [3].

However, a large amount of literature concerning financial development and income inequality believes that financial development may reduce income inequality by focusing on increasing the income of the poorest people $[4,5]$. It is also possible to expand income inequality through unequal financing channels [6,7], Greenwood and Jovanovic's model predicts the inverted U-shaped relationship between financial development and income inequality [8].

When financial markets and financial institutions operate well, they allow all market participants to form effective investments by allocating funds to more productive uses, which can boost economic growth and reduce income inequality and poverty. Conversely, if financial markets are not functioning correctly and poor people have limited access to financial services, financial development may not reduce inequality and poverty [9].

Conroy argues that financial exclusion is a process that prevents the poor and disadvantaged social groups from entering their country's formal financial system [10]. Financial inclusion refers to the process of ensuring that all members of an economy can easily visit, access, and use the formal financial system. Financial inclusion emphasizes providing financial services to all parts of society at an affordable cost. Increasing the access of the poor to financial services was often regarded as an effective tool to reduce poverty and income inequality. Therefore, financial inclusion growth would undoubtedly help reduce income inequality and reduce poverty. Financial inclusion significantly promoted financial stability by reducing potential risks and realizing sustainable economic growth. Ultimately, family well-being is improved by reducing the incidence of frailty and poverty. Financial inclusion is generally considered a critical factor in achieving growth inclusion Access to finance allows economic entities to make long-term consumption and investment decisions, engage in productive activities, and respond to unexpected short-term shocks, thereby reducing poverty incidence and promoting income equality. Park et al. evaluated various macroeconomic variables and country-specific factors affecting the degree of financial inclusion in 37 developing Asian countries, and confirmed that financial inclusion significantly reduced poverty and reduced income inequality [11]. Burgess and Pande [12], Brune et al. [13], Allen et al. [14], and Erlando et al. [15], based on experiences from India, Malawi, Kenya, and Indonesia, respectively, substantiate the fact that financial inclusion has achieved poverty reduction and reduced income inequality by increasing rural banking sites and broadening access to financing of rural areas.

The World Bank argues that an inclusive financial system contributes to the highefficiency allocation of financial resources and provides individuals with the correct channels to overcome those factors that pose challenges to stability and growth, equitable distribution of resources, poverty reduction, and achieving sustainable development [16]. Sustainable economic growth can be effectively achieved by engaging excluded groups with informal financial services such as security savings practices, credit and payment, insurance and pension, and other financial products. Admittedly, Dhrifi (2013), Seven and Coskun (2016), and Neaime and Gaysse (2018) found that financial inclusion does not have a significant influence on poverty and income inequality $[7,17,18]$. Some studies have also explained the mechanism by which financial inclusion enhances poverty. Li A et al. confirmed that financial inclusion might limit sustainable development under economic globalization and climate change [19]. Affected by economic globalization and climate change, the complex interaction between the components of the social ecosystem may affect the ability of rural people to maintain the income and livelihood of smallholder agri- 
culture and animal husbandry, so that inclusive finance such as microfinance has become a poisoned challenge for smallholders. Profits were uncertain when facing grassland area constraints to adaptation [20], high feed costs [21], complex financial markets, a volatile market [22], and unstable climate [19]. When encountering bad risks, petty loan farmers in India, China, and other places under pressure to repay loans have to sell low-grade agricultural products or even sell assets at a low price to raise money, thus suffering substantial economic losses, even sliding back into poverty [23].

The existing literature has determined the capital channel and threshold effects of financial development affecting poverty. Financial inclusion provides vulnerable and low-income groups with opportunities to build savings and investment, and access to credit [24]. It enables them to respond effectively to income shocks and helps to overcome unforeseen emergencies such as disease or unemployment. Stiglitz mentioned that financial development could directly contribute to poverty reduction by improving deposit and credit facilities for the poor and optimizing the allocation of resources [25]. However, the poverty reduction mechanism of financial development also makes financial development vulnerable to impact, which directly or indirectly hinders its role in poverty reduction. As a result, financial turmoil has hurt individuals directly or indirectly [26].

Among the United Nations sustainable development goals, the top two are poverty eradication and hunger eradication, which are essential prerequisites for sustainable development, and grain security plays a crucial role in both. It should be noted that a large number of popular studies in the past also demonstrate that the influencing factors of food security are very complex. The current lack of coordinated focus on grain legumes has compromised human health, nutritional security and sustainable food production [27]. Climate change, food storage, and farmland transformation will all have a far-reaching impacts on food security [28-30]. From a novel perspective, this study focuses on the impact and mechanism of financial inclusion on grain security efficiency to analyze the impact of financial inclusion achieving sustainable development goals.

This paper's main work and marginal contributions are as follows: Based on the public data of 121 countries from 2015 to 2019, the financial inclusion index, grain security efficiency, and its two-stage decomposition efficiency are measured by using the entropy weight method and Two-stage DEA model, respectively. On this basis, the panel regression model and mediating effect model are established to analyze the impact and mechanism of financial inclusiveness on food security efficiency and its two-stage decomposition indicators through OLS and iv-2sls estimation methods. The empirical results indicate that: (1) Financial inclusion will have a significantly positive effect on the efficiency of grain security. (2) The promotion effect of financial inclusion on grain ecological efficiency is mainly reflected in improving grain distribution efficiency. Specifically, the promotion effect of financial inclusion on grain distribution efficiency is about twice that on grain production efficiency. (3) Financial inclusion promotes the efficiency of grain distribution through the effects of the income distribution, income growth, and consumption capacity upgrading to achieve the development of grain security.

\section{Research Design}

\subsection{Theoretical Analysis and Research Hypotheses}

According to the theoretical analysis and empirical test of the above literature, improving financial inclusion will significantly reduce poverty and income inequality. According to "the Law of Diminishing Marginal Propensity to Consume" and "Engel's law", the reduction of poverty will improve the ability of residents, especially low-income groups, to buy grain, and the reduction of residents' income inequality will effectively reduce the inequality of residents' consumption level, especially the inequality of grain consumption level. It can be observed that the improvement of financial inclusion may promote the grain security capacity of low-income groups from a micro perspective, promote the balance of national grain distribution from a macro perspective, and jointly improve the efficiency of grain security in a country. Therefore, the first hypothesis put forward in this study is that: 
Hypothesis 1 (H1). The financial inclusion of sample countries can promote grain security efficiency.

Achieving "sustainable development goal 2"- eradicating hunger, achieving grain security, improving nutrition, and promoting sustainable agriculture-can be divided into two links. The first is to ensure that there is enough grain, and the second is to ensure that grain is reasonably distributed to achieve sufficient and balanced grain security capacity. Given this, this study decomposes grain security efficiency into grain production efficiency and grain distribution efficiency. It examines the impact of financial inclusion on realizing "sustainable development goal 2" from the perspective of the impact mechanism of financial inclusion on grain production efficiency and grain distribution efficiency. On account of the consumption attribute of grain distribution and the investment attribute of agricultural production, financial institutions will prefer to support grain production rather than grain consumption to maintain and increase the value of their funds. On the contrary, the improvement of financial inclusion can make up for the limitation of traditional financial institutions' insufficient protection for vulnerable groups based on commercial considerations. Therefore, it can be expected that the improvement of financial inclusion will improve grain distribution efficiency more than that of financial inclusion. The promotion of financial inclusion on grain security efficiency is mainly reflected in distribution rather than production. Therefore, this study puts forward the second hypothesis:

Hypothesis 2 (H2). The role of financial inclusion in promoting grain security efficiency is mainly reflected in promoting grain distribution efficiency.

From a macro perspective, financial inclusion helps to promote economic growth, maintain employment, income distribution, and financial stability [31]. From a micro perspective, financial inclusion can improve absorption of financial shocks, smooth consumption, accumulate assets, and invest in health and education by increasing the intensity of petty loans [32], promoting the convenience of remittance [33,34], reducing the cost of capital use [2,35], and decreasing transaction payment costs [36]. Financial inclusion is mainly aimed at people who have difficulty reaching financial services (mainly low-income people). After obtaining inclusive financial services, low-income people can not only improve their wealth, but also obtain more loans for personal and family development [37]. In this case, the income of low-income people can be improved and food can be supplied to them to a greater extent. In addition, financial inclusion promotes personal consumption loans, which can promote the consumption level of the whole society, including food consumption. Therefore, this study puts forward the third hypothesis:

Hypothesis 3 (H3). Financial inclusion promotes grain distribution efficiency through residents' income distribution, growth, and consumption capacity upgrading effect.

\subsection{Research Methods and Analytical Logic}

This study intends to construct the financial inclusion index of the sample countries by weighting with entropy weight and calculating the grain security efficiency of the sample countries (including grain production efficiency and grain distribution efficiency) by the two-stage DEA method, and then investigate the impact of financial inclusion on grain security efficiency and its impact mechanism based on the panel data of the sample countries.

In terms of financial inclusion indicators, this study carries out statistical analysis concerning the financial access Survey (FAS) implemented by the International Monetary Fund. After selecting the fundamental indicators, comprehensive indicators are weighting to reflect the countries' financial inclusion and annual changes. The Financial Access Survey (FAS), launched in 2009, is a supply-side dataset on the access and use of financial services. It aims to support decision-makers to measure and monitor financial inclusion and make horizontal comparisons. The data set covers 189 countries, spans more than ten years, and contains 121 time series on financial access and use, including mobile money and 
gender-disaggregated data on basic financial services. The Financial Access Survey is an internationally recognized authoritative basic data set reflecting the financial inclusion of various countries. The Sustainable Development Goal indicator framework adopts two FAS indicators, and the G20 financial inclusion indicator system adopts nine FAS indicators.

In terms of grain security efficiency indicators, this study intends to measure the grain security efficiency of sample countries from the perspectives of production and distribution based on the Two-stage DEA method. In terms of production links, capital factors such as land and labour input are the main production factors of grain production. The improvement of financial inclusion may improve the capital stock of agricultural production by providing petty loans and other financial support to various agricultural production entities, and increasing agrarian labor input due to the employment brought by investment growth. Therefore, the financial inclusion of sample countries has an important impact on grain production. From the aspect of distribution, improving financial inclusion may promote grain trade and circulation, and effectively guarantee residents' income and stable consumption expectations. Therefore, the financial inclusion of the sample countries has an important impact on the efficiency of grain distribution.

Then, based on the above indicators, this study intends to use an econometric model to analyze the impact degree and impact mechanism of financial inclusion on grain security efficiency and its two-stage indicators in sample countries.

\subsection{Variable Description and Data Sources}

Based on the research ideas and data availability, this study's temporal and spatial dimensions are 121 sample countries from 2015 to 2019. The variables are set as follows: (1) The grain security efficiency and its two-stage decomposition indicators (grain production efficiency and grain distribution efficiency) of various countries are selected as dependent variables. All three are DEA analysis output indicators, and their maximum value is 1 , indicating that they are frontier. (2) The financial inclusion of various countries is selected as the independent variable, and the selected indicators are calculated by entropy weight method based on Financial Access Survey. (3) Six covariants are used to control the external factors affecting a country's grain security efficiency except for financial inclusion, including economic development level, expressed in the logarithm of GDP,; Population Density, expressed in person/1000 ha, Capital Stock Level, expressed by the capital stock of each country given by PWT10.0, Price Level of Household consumption, measured by 2017 US GDPo Price Level = 1, Real Internal Rate of Return, expressed by the actual internal rate of return of each country given by PWT10.0, and the Proportion of Industrial Added Value in GDP.(4) The financial development index of various countries is selected as an instrumental variable to solve the endogenous problem in regression, which is used to eliminate the endogenous caused by the development of finance itself. The financial development index is from the IMF Database. (5) In the mechanism analysis part, three mediating variables are selected to refer to residents' income equality, residents' income level, and social consumption ability. The Gini coefficient (GINI) of each country is the indicator variable. The per capita gross national income (GNI) (current price in US dollars), measured by the chart set method, is the indicator variable of residents' income level. The social consumption capacity selects the per capita actual consumption of households and government (Ccon), calculated according to the current purchasing power parity as the indicator variable. All data are from publicly acquired platforms. The interpolation method is used to complete some missing values according to the variation trend of variables [38,39].

Table 1 lists the index names, index abbreviations, data sources, and preliminary descriptive statistics corresponding to the dependent variables, independent variables, covariants, instrumental variables, and mediating variables. 
Table 1. Variable data source and descriptive statistics.

\begin{tabular}{|c|c|c|c|c|c|c|c|}
\hline Variable & Abbr. & Unit & Mean & Min & Max & Std & Source \\
\hline Grain Security Efficiency & Gs-eff & - & 0.564 & 0.144 & 1 & 0.161 & 2-stage DEA \\
\hline Grain Production Efficiency & Gp-eff & - & 0.234 & 0.011 & 1 & 0.237 & 2-stage DEA \\
\hline $\begin{array}{l}\text { Grain Distribution } \\
\text { Efficiency }\end{array}$ & Gd-eff & - & 0.901 & 0.195 & 1 & 0.151 & 2-stage DEA \\
\hline Financial Inclusion Index & Findex & - & 0 & -1.217 & 6.870 & 1 & $\begin{array}{c}\text { IMF } \\
\text { Database }\end{array}$ \\
\hline $\begin{array}{c}\text { Economic Development } \\
\text { Level }\end{array}$ & gdp & ln (millions USD) & 11.378 & 6.873 & 16.880 & 2.055 & PWT10.0 \\
\hline Population density & den & person/1000 ha & 0 & -2.313 & 3.750 & 1 & PWT10.0 \\
\hline Capital Stock Level & cap & ln (millions USD) & 13.431 & 8.953 & 18.217 & 1.986 & PWT10.0 \\
\hline $\begin{array}{l}\text { The price level of household } \\
\text { consumption }\end{array}$ & plc & - & 0 & -0.352 & 16.022 & 1 & PWT10.0 \\
\hline Real Internal Rate of Return & irr & - & 0 & -1.390 & 5.703 & 1 & PWT10.0 \\
\hline $\begin{array}{c}\text { The proportion of Industrial } \\
\text { Added Value }\end{array}$ & ind & - & 0 & -1.885 & 3.937 & 1 & World Bank \\
\hline $\begin{array}{c}\text { Financial Development } \\
\text { Index }\end{array}$ & FDI & - & 0.381 & 0.044 & 0.974 & 0.233 & $\begin{array}{c}\text { IMF } \\
\text { Database }\end{array}$ \\
\hline Gini coefficient & GINI & - & 0.354 & 0.133 & 0.629 & 0.086 & World Bank \\
\hline $\begin{array}{l}\text { Per Capita Gross National } \\
\text { Income }\end{array}$ & GNI & 1000 USD/person & 16.715 & 0.47 & 92.91 & 19.71 & World Bank \\
\hline $\begin{array}{l}\text { Per Consumer Power of } \\
\text { Society }\end{array}$ & Ccon & 1000 USD/person & 16.703 & 0.324 & 51.133 & 11.904 & PWT10.0 \\
\hline
\end{tabular}

\section{Pretreatment of Core Variables}

\subsection{Measurement of Financial Inclusion Index}

As the independent variable of this paper, the financial inclusion of various countries is measured by the entropy weight method [40]. The steps are as follows: Step 1, normalization of the index value. The data of each index is normalized. Based on $605(121 \times 5)$ evaluated objects and the nine evaluation indices provided in this paper, the normalization matrix is as follows:

$$
X=\left[\begin{array}{cccc}
x_{1,1} & x_{1,2} & \cdots & x_{1,9} \\
x_{2,1} & x_{2,2} & \cdots & x_{2,9} \\
\vdots & \vdots & \ddots & \vdots \\
x_{605,1} & x_{605,2} & \cdots & x_{605,9}
\end{array}\right]
$$

The matrix $X$ was standardized and the standardization formula is as follows:

$$
z_{i, j}=\frac{x_{i, j}-\min \left\{x_{1, j}, x_{2, j}, \cdots, x_{605 j}\right\}}{\max \left\{x_{1, j}, x_{2, j}, \cdots, x_{605, j}\right\}-\min \left\{x_{1, j}, x_{2, j}, \cdots, x_{605, j}\right\}}
$$

In Step 2, the weight for $i$-th sample under $j$-th index is calculated and considered as the probability to be used in the relative entropy calculation. Based on the previous step, the probability matrix $P$ is calculated, and each element of $P$ is as follows:

$$
P_{i, j}=\frac{z_{i, j}}{\sum_{i=1}^{605} z_{i, j}}
$$

In Step 3, the information entropy of each index is calculated, and the information utility value is calculated and normalized to obtain the entropy weight of each index. For $j$-th indicator, its information entropy is computed as:

$$
e_{j}=-\frac{1}{\ln 605} \sum_{i=1}^{605} p_{i, j} \ln \left(p_{i, j}\right)
$$


Therefore, the greater the $e_{j}$, the greater the information entropy of index $j$-th, and the smaller the corresponding information. Defining the information utility $d_{j}=1-e_{j}$. The information utility value is normalized and gets the entropy weight of each index.

$$
W_{j}=\frac{d_{j}}{\sum_{j=1}^{9} d_{j}}
$$

According to the above steps, the weight of nine evaluation indices can be obtained, as provided in Table 2. The final indicators were summed by weight to obtain the level of financial inclusion for each sample country in each period.

Table 2. Composition of financial inclusion index.

\begin{tabular}{|c|c|c|}
\hline Primary Indicator & Secondary Indicator & Weight \\
\hline \multirow{2}{*}{$\begin{array}{l}\text { Small deposits and } \\
\text { withdrawals }\end{array}$} & ATMs $/ 1000 \mathrm{~km}^{2}$ & 0.36405 \\
\hline & ATMs $/ 100,000$ adults & 0.04143 \\
\hline \multirow{2}{*}{ Service network coverage } & Commercial bank branches $/ 1000 \mathrm{~km}^{2}$ & 0.27250 \\
\hline & Commercial bank branches $/ 100,000$ adults & 0.03764 \\
\hline \multirow{5}{*}{ Financial business volume } & Debit cards / 1000 adults & 0.03368 \\
\hline & $\begin{array}{l}\text { Outstanding deposits of household sector } \\
\text { with commercial banks (\% of GDP) }\end{array}$ & 0.09228 \\
\hline & $\begin{array}{l}\text { Outstanding deposits with commercial banks } \\
\text { (\% of GDP) }\end{array}$ & 0.03608 \\
\hline & $\begin{array}{l}\text { Outstanding deposits with other deposit } \\
\text { takers ( } \% \text { of GDP) }\end{array}$ & 0.08673 \\
\hline & $\begin{array}{l}\text { Outstanding loans from commercial banks } \\
\qquad(\% \text { of GDP) }\end{array}$ & 0.03561 \\
\hline
\end{tabular}

Figure 2 reports the mean distribution of financial inclusion levels for the sample countries over the study period. It can be found that there is a certain association between financial inclusion and the level of economic development, with lower levels of financial inclusion in Africa, South America, and Central Asia, and higher levels of financial inclusion in North America, Europe, and East Asia. (The figure includes only the rough distribution of the core variables of the sample countries in this paper, excluding water areas, sea areas, and other areas, does not represent the author's political position, and cannot be used as a map).

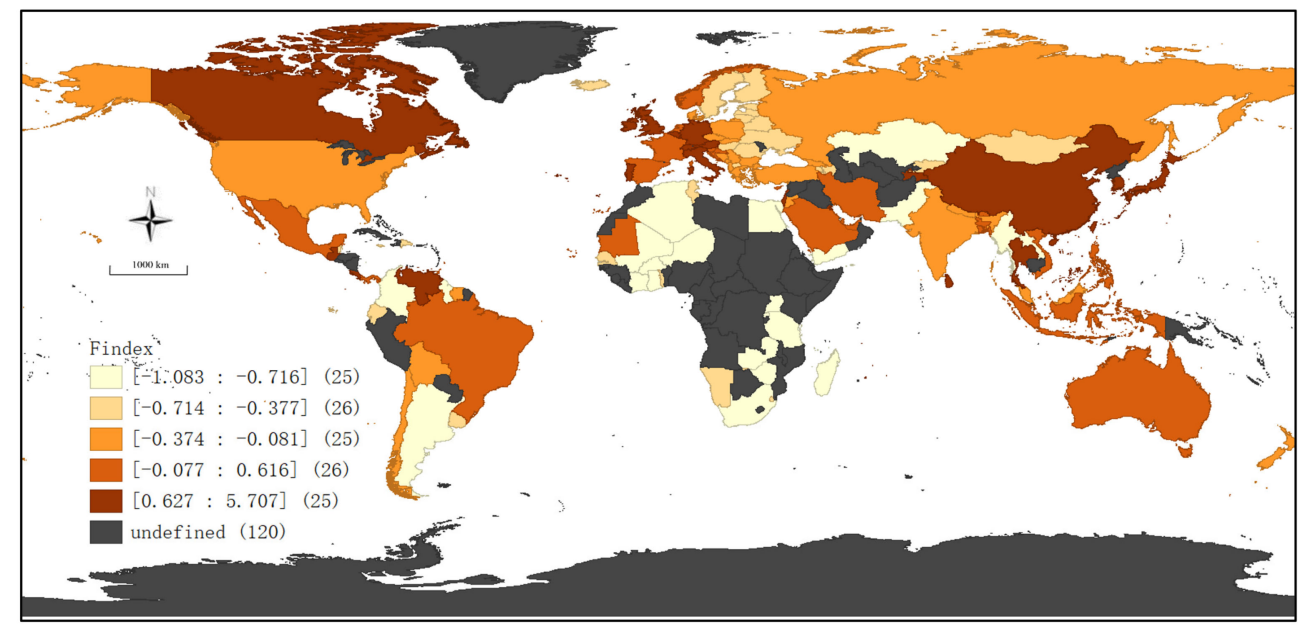

Figure 2. Mean Findex values from 2015 to 2019. 


\subsection{Measurement of Food Security Efficiency}

As the dependent variable of this paper, the grain security efficiency and its twostage decomposition indices (grain production efficiency and grain distribution efficiency) are measured by the two-stage Data Envelopment Analysis (DEA) model based on the CCR radial distance function and analyzed by Maxdea Ultra software [41-43]. Data Envelopment Analysis (DEA) was proposed in 1978 to evaluate the relative efficiency of a group of decision-making units with multiple inputs and outputs [44,45]. In this paper, the Two-stage DEA is calculated by the method of network DEA. In the decision-making unit involved in Network DEA, two DEA nodes code 1 and code 2 are set. The output of code 1 (indirect output) is the input of code 2 (indirect input). The indirect variable is also called the intermediate variable. The DEA calculation can obtain the efficiency value of the two stages and the overall efficiency value [46,47]. In this paper, code 1 takes the sample country per capita cultivated land area and proportion of agricultural labour in total population as input and per capita grain output as the expected output. The grain production efficiency in the first stage can be measured and calculated. Based on the idea of ensuring grain consumption, eliminating hunger, and ensuring nutritional needs to maintain human body health, this study takes the population's nutritional security level and basic health level in the sample countries as the characterization variables of grain distribution. Code 2 takes the output of code 1 as indirect input, plus grain import per capacity as additional input, normal nutrition rate of the total population as expected output, and prevalence of underweight, weight for age ( $\%$ of children under 5 ), prevalence of stopping, height for age (\% of children under 5), mortality rate, under 5 (per 1000 live births), and prevalence of wasting, weight for height (\% of children under 5 ) as unexpected output, from which the grain distribution efficiency in the second stage can be measured. The comprehensive efficiency of the first stage and second stage is the grain security efficiency of the main dependent variable in this paper. The specific Two-stage DEA process is provided in Figure 3, and the indicator setting is reported in Table 3.

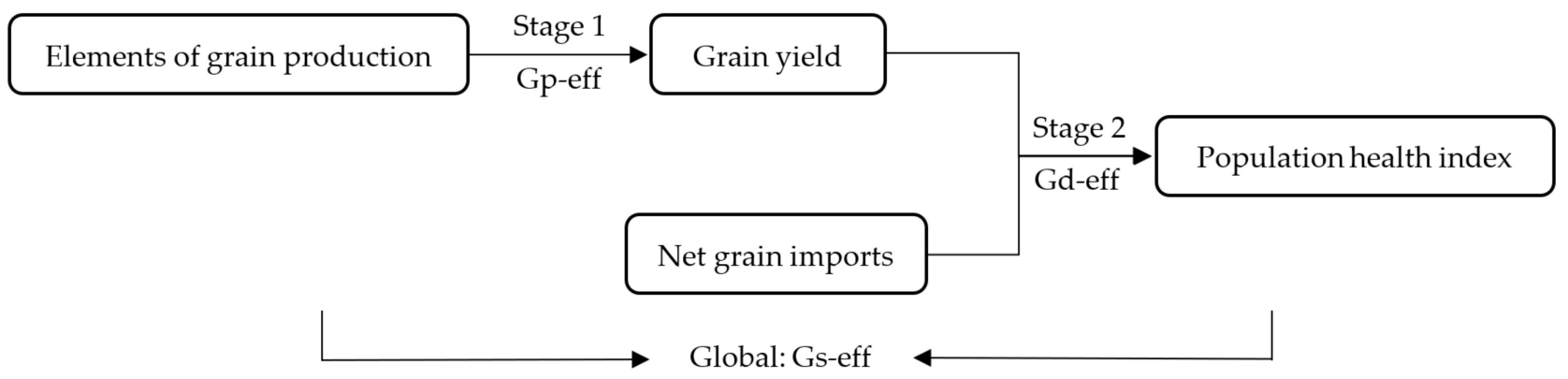

Figure 3. Diagram of Two-stage DEA.

Table 3. Measurement of input and output index by Two-stage DEA.

\begin{tabular}{|c|c|c|c|}
\hline First-Grade Index & Second-Grade Index & Third-Grade Index & Sources \\
\hline \multicolumn{4}{|c|}{ Stage 1} \\
\hline \multirow{2}{*}{ Input index } & Land & Per capita cultivated land area & FAOSTAT \\
\hline & Labor & $\begin{array}{c}\text { The proportion of agricultural labor in } \\
\text { total population }\end{array}$ & FAOSTAT \\
\hline \multirow[t]{2}{*}{ Output index } & Yield & Per capita grain output & FAOSTAT \\
\hline & & 2 & \\
\hline \multirow{2}{*}{ Input index } & Yield & Per capita grain output & FAOSTAT \\
\hline & Net import & Grain import per capita & FAOSTAT \\
\hline
\end{tabular}


Table 3. Cont

\begin{tabular}{|c|c|c|c|}
\hline First-Grade Index & Second-Grade Index & Third-Grade Index & Sources \\
\hline \multicolumn{4}{|c|}{ Stage 2} \\
\hline \multirow{5}{*}{ Output index } & Desirable output & $\begin{array}{l}\text { Normal nutrition rate of the total } \\
\text { population }\end{array}$ & World Bank \\
\hline & \multirow{4}{*}{ Undesirable output } & $\begin{array}{l}\text { Prevalence of underweight, weight for } \\
\text { age (\% of children under } 5)\end{array}$ & World Bank \\
\hline & & $\begin{array}{l}\text { Prevalence of stunting, height for age } \\
\text { (\% of children under } 5)\end{array}$ & World Bank \\
\hline & & $\begin{array}{l}\text { Mortality rate, under-5 (per } 1000 \text { live } \\
\text { births) }\end{array}$ & World Bank \\
\hline & & $\begin{array}{l}\text { Prevalence of wasting, weight for } \\
\text { height (\% of children under } 5)\end{array}$ & World Bank \\
\hline
\end{tabular}

Figures 4 and 5, respectively, report the average distribution of grain security efficiency, grain production efficiency, and grain distribution efficiency of sample countries during the investigation period. It can be found that the spatial distribution of grain security efficiency and its decomposition indicators are synchronized with financial inclusion to a certain extent. Specifically, areas with better economic development usually have higher grain security efficiency, while the grain security efficiency in Africa remains low. In addition, there is a certain degree of heterogeneity in the spatial distribution of grain production efficiency and grain distribution efficiency. Therefore, we can predict that the impact of financial inclusion on the two-stage indicators of grain security efficiency is different. (The figure illustrates only the rough distribution of the core variables of the sample countries in this paper, excluding water areas, sea areas, and other areas, does not represent the author's political position, and cannot be used as a map).

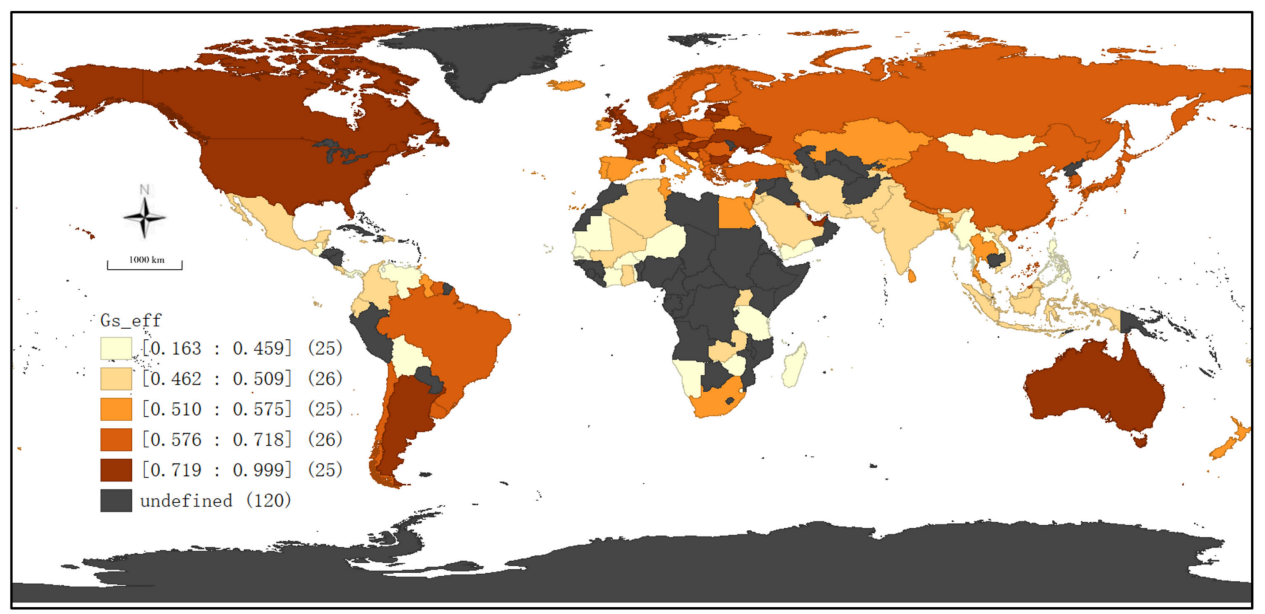

Figure 4. Mean Gs-eff values from 2014 to 2019. 


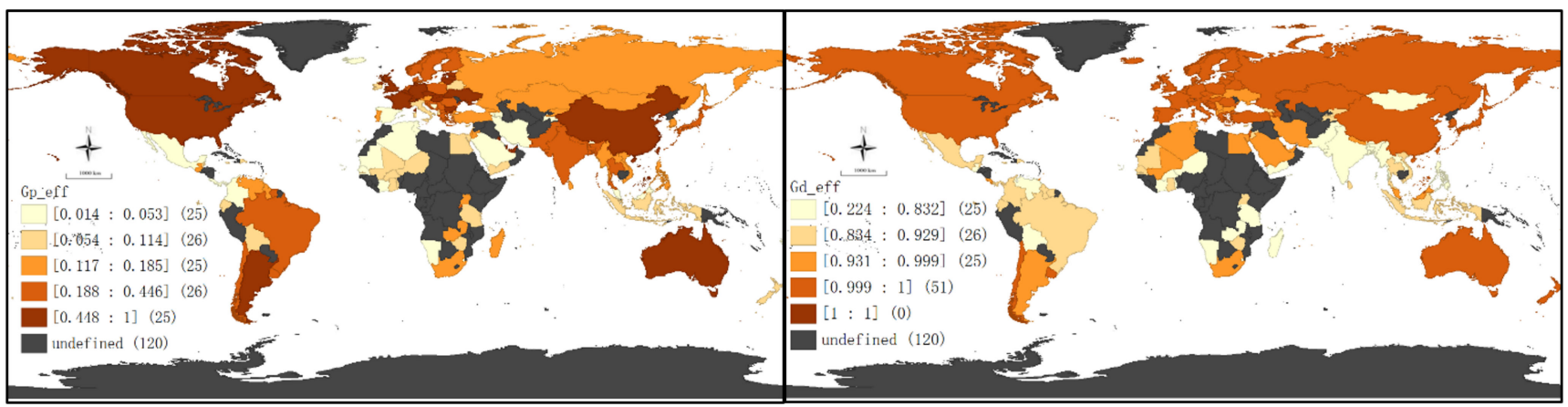

Figure 5. Mean Gp-eff and Gd-eff values from 2014 to 2019.

\section{Econometric Examination of the Impact of Financial Inclusion on Grain Security Efficiency}

\subsection{Model Specification}

Based on the research hypothesis, this paper uses the fixed effect regression model to verify the impact of financial inclusion on grain security efficiency and its two-stage decomposition indicators. Compared with OLS estimation, the individual fixed effect model can control the influence of macro factors that do not change with regions on the regression results. The regression model of Equations (6)-(8) is obtained to fit and analyze the relevant data of the sample countries:

$$
\begin{aligned}
& \text { Gs_eff } f_{i t}=\alpha_{0}+\alpha_{1} \text { Findex }_{i t}+\alpha_{2} X_{i t}+\pi_{i}+\varepsilon_{i t} \\
& \text { Gp_eff } f_{i t}=\beta_{0}+\beta_{1} \text { Findex }_{i t}+\beta_{2} X_{i t}+\pi_{i}+\delta_{i t} \\
& \text { Gd_eff } f_{i t}=\gamma_{0}+\gamma_{1} \text { Findex }_{i t}+\gamma_{2} X_{i t}+\pi_{i}+\mu_{i t}
\end{aligned}
$$

In Equations (6)-(8), $i$ represents the national individual, $t$ means year and time, Gs_eff, Gp_eff and $G d \_e f f$ are dependent variables, which are grain security efficiency, grain production efficiency, and grain distribution efficiency. Findex is the independent variable; $X$ is a covariant that may affect the dependent variable; $\pi_{i}$ represents individual fixed effect; $\varepsilon_{i t}, \delta_{i t}$ and are $\mu_{i t}$ are the error terms; $\alpha_{1}, \beta_{1}$ and $\gamma_{1}$ represent the direction and intensity of the impact on grain security efficiency, grain production efficiency, and grain distribution efficiency, which are the key parameters of this paper.

In addition, when directly analyzing the impact of financial inclusion on grain security efficiency based on the above benchmark model, the endogeneity of financial inclusion variables must be discussed. It is necessary to explore whether the grain security efficiency of countries will affect their financial inclusive development level. It is undeniable that the higher the grain security efficiency of a country, the more conducive to sustainable economic and social development. The more perfect its economic and social development is, the higher the corresponding level of financial development, and the internal demand for financial inclusion will continue to grow. Thus, a mechanism of "the improvement of grain security efficiency forces the development of financial inclusion through economic and social development" is formed. In this case, there may be a certain degree of "reverse causality" between the core dependent variable and the independent variable in Equations (6)-(8). Specifically, on the one hand, financial inclusion may promote grain security efficiency through residents' income distribution effect, residents' income growth effect, and consumption capacity upgrading effect. On the other hand, grain security efficiency itself will also affect financial development by promoting population growth, prolonging life expectancy, changing population age structure, and population distribution structure, especially the demand for financial inclusion and the supply and security of financial inclusion. Searching appropriate instrumental variables for the core independent variable financial inclusion effectively alleviates the above endogenous problems. The basic theory of econometrics requires that the instrumental variables should be highly 
related to endogenous variables and have a direct impact on dependent variables. Based on this understanding, this paper intends to take the financial development index as an instrumental variable of financial inclusion.

Based on the three elements of financial depth, financial accessibility, and financial efficiency, the IMF calculated the financial development index of nearly 200 countries worldwide to comprehensively evaluate the strength of the financial industry and the development level of financial services in various countries. Financial development level and financial inclusion are important indicators based on objective reality to reflect the development degree of the financial industry in various countries, which must be highly correlated. However, financial development level and financial inclusion are two groups of statistical indices compiled, respectively, based on different data sources and calculation systems, and they are not directly related. It can be observed that we can attempt to take the level of financial development as a candidate instrumental variable for a country's financial inclusion. Considering that the possible "reverse causality" is formed through the path of food security efficiency affecting sustainable economic and social development, economic and social development promoting financial development, and thus promoting financial inclusiveness, it is effective to use the financial development index as an instrumental variable to block "reverse causality." Therefore, choosing the financial development index as the instrumental variable of financial inclusion can meet the correlation hypothesis of effective instrumental variables, on the one hand [2]; on the other hand, it can also well meet the exogenous hypothesis of effective instrumental variables.

In summary, to better investigate the impact of financial inclusion on grain security efficiency quantitatively, this paper uses a two-stage least squares regression model (2SLS) to set the model:

$$
\begin{gathered}
\text { Findex }_{i t}=\alpha_{0}+\alpha_{1} \text { FDI }_{i t}+\alpha_{2} X_{i t}+\sigma_{i t} \\
\text { Gs_eff }_{i t}=\beta_{0}+\beta_{1} \text { Findex }_{i t}+\beta_{2} X_{i t}+\mu_{i t}
\end{gathered}
$$

In Equations (9) and (10), FDI is the financial development index as an instrumental variable, other indices are consistent with those in Equations (6)-(8); $\beta_{1}$ represents the impact coefficient of financial inclusion on grain security efficiency, which is the key parameter of this paper. The 2SLS test form of the impact of financial inclusion on grain production efficiency and grain distribution efficiency is the same as Equations (9) and (10), so it will no longer be repeated.

\subsection{Result of Parameter Estimation}

This paper uses the benchmark panel fixed effect regression model (FE) [48,49], Equations (6)-(8), to analyze the impact of financial inclusion on grain security efficiency and its two-stage decomposition efficiency. According to the model specification, the estimation results are presented in Table 4.

It can be observed from Table 4 that financial inclusion has a significant role in promoting the efficiency of grain security, but there are differences in the two stages. Specifically, without considering the covariant, financial inclusion significantly promotes grain security efficiency $\left(\alpha_{1}=0.037, P=0.000\right)$. Financial inclusion also significantly promotes grain production efficiency $\left(\beta_{1}=0.044, P=0.000\right)$ and $\left(\gamma_{1}=0.043, P=0.000\right)$. Considering the covariant and controlling individuals, financial inclusion also significantly promotes the efficiency of grain security $\left(\alpha_{1}=0.070, P=0.000\right)$ and grain efficiency $\left(\beta_{1}=0.074, P=0.003\right)$. However, the impact on grain distribution $\left(\gamma_{1}=0.009, P=0.127\right)$ is not significant. 
Table 4. The estimation results for the benchmark regression.

\begin{tabular}{ccccccc}
\hline \multirow{2}{*}{ Items } & \multicolumn{2}{c}{ Grain Security Efficiency } & \multicolumn{2}{c}{ Grain Production Efficiency } & \multicolumn{2}{c}{ Grain Distribution Efficiency } \\
\cline { 2 - 6 } & $\mathbf{( 1 )}$ & $\mathbf{( 2 )}$ & $\mathbf{( 3 )}$ & $\mathbf{( 4 )}$ & $\mathbf{( 5 )}$ & $\mathbf{( 6 )}$ \\
\hline Findex & $0.037^{* * *}(5.82)$ & $0.070^{* * *}(4.86)$ & $0.044^{* * *}(4.58)$ & $0.074^{* * *}(3.00)$ & $0.043^{* * *}(7.14)$ & $0.009(1.53)$ \\
gdp & - & $0.001(0.05)$ & - & $-0.009(-0.25)$ & - & $0.008(0.86)$ \\
den & - & $0.152(1.31)$ & - & $0.230(1.16)$ & - & $0.060(1.22)$ \\
cap & - & $0.034(1.42)$ & - & $0.027(0.64)$ & - & $0.038^{* * *}(3.72)$ \\
plc & - & $-0.005(-1.06)$ & - & $0.008(1.04)$ & $-0.015^{* * *}$ & $(-8.46)$ \\
irr & - & $0.003(0.25)$ & - & $0.008(0.40)$ & - & $-0.003(-0.64)$ \\
ind & - & $-0.002(-0.16)$ & - & $-0.005(-0.25)$ & - & $0.001(0.15)$ \\
FE & No & Yes & No & Yes & No & Yes \\
N & 605 & 605 & 605 & 605 & 605 & 605 \\
R-squared & 0.0532 & 0.1399 & 0.0337 & 0.0708 & 0.0779 & 0.3886 \\
\hline
\end{tabular}

Notes: ${ }^{* * *}$ stand for significant levels of $1 \%$, and the values in brackets are $t$-values.

Based on the above analysis, the endogenous problem between core variables may be ignored when directly considering the impact of financial inclusion on grain security efficiency. Tables 5 and 6 display the 2SLS regression results of instrumental variables. Firstly, the correlation between instrumental variable financial development index and endogenous variable financial inclusion is investigated. The RKF test statistic is positive, and the $\mathrm{P}$-value is 0 , indicating no weak instrumental variable problem.

Table 5. The estimation results for the first stage of 2SLS.

\begin{tabular}{ccc}
\hline \multirow{2}{*}{ Items } & \multicolumn{2}{c}{ Financial Inclusion } \\
\cline { 2 - 3 } & $\mathbf{( 1 )}$ & $\mathbf{( 2 )}$ \\
\hline FDI & $2.163^{* * *}(13.57)$ & $2.071^{* * *}(7.48)$ \\
gdp & - & $-0.073(-0.43)$ \\
den & - & $0.141^{* * *}(6.71)$ \\
plc & - & $0.070(0.49)$ \\
irr & - & $0.274^{* * *}(5.64)$ \\
ind & - & $-0.016(-0.34)$ \\
N & - & $0.149^{* * *}(3.60)$ \\
R-squared & 605 & 605 \\
Notes: *** stand for significant levels of 1\%, and the values in brackets are $t$-values. & 0.3604 \\
\hline
\end{tabular}

Table 6. The estimation results for the second stage of 2SLS.

\begin{tabular}{|c|c|c|c|c|c|c|}
\hline \multirow{2}{*}{ Items } & \multicolumn{2}{|c|}{ Grain Security Efficiency } & \multicolumn{2}{|c|}{ Grain Production Efficiency } & \multicolumn{2}{|c|}{ Grain Distribution Efficiency } \\
\hline & (1) & (2) & (3) & (4) & (5) & (6) \\
\hline Findex & $0.169^{* * *}(10.35)$ & $0.127^{* * *}(5.05)$ & $0.188^{* * *}(8.30)$ & $0.073^{* *}(2.56)$ & $0.145^{* * *}(10.53)$ & $0.157^{* * *}(6.01)$ \\
\hline gdp & - & $0.031(1.19)$ & - & $0.091^{* * *}(3.81)$ & - & $-0.012(-0.43)$ \\
\hline den & - & $0.007(0.96)$ & - & $0.035^{* * *}(3.93)$ & - & $\begin{array}{c}-0.014 * \\
(-1.87)\end{array}$ \\
\hline cap & - & $-0.018(-0.76)$ & - & $\begin{array}{c}-0.064^{* * *} \\
(-2.70)\end{array}$ & - & $0.015(0.61)$ \\
\hline plc & - & $\begin{array}{c}-0.057 \text { *** } \\
(-7.22)\end{array}$ & - & $\begin{array}{c}-0.044^{* * *} \\
(-5.05)\end{array}$ & - & $\begin{array}{c}-0.066^{* * *} \\
(-6.92)\end{array}$ \\
\hline irr & - & $\begin{array}{c}-0.024^{* * *} \\
(-2.71)\end{array}$ & - & $\begin{array}{c}-0.060 * * * \\
(-6.86)\end{array}$ & - & $0.006(0.63)$ \\
\hline ind & - & $0.001(-0.08)$ & - & $0.019(1.31)$ & - & $-0.012(-1.22)$ \\
\hline $\mathrm{N}$ & 605 & 605 & 605 & 605 & 605 & 605 \\
\hline Root MSE & 0.2055 & 0.1712 & 0.2744 & 0.2163 & 0.1783 & 0.1710 \\
\hline
\end{tabular}


The one-stage regression results in Table 5 demonstrate an obvious correlation between the instrumental variable financial development index and the endogenous variable financial inclusion, whether or not the covariant is added. There is a significant positive correlation between financial development level and financial inclusion. The regression results of the first stage meet the correlation hypothesis of the instrumental variables. It should be noted that in the first stage results of Table 5, column (1) corresponds to columns (1), (3), and (5) in the second stage of Table 6, and column (2) in Table 5 corresponds to columns (2), (4), and (6) in the second stage of Table 6.

According to the second stage regression results of 2SLS in Table 6, financial inclusion still promotes grain security efficiency. However, there are differences in the two stages, and this difference is also different from the analysis results of the panel fixed effect regression model. Specifically, when considering instrumental variables but not covariant, financial inclusion significantly promotes the grain security efficiency $\left(\beta_{1}=0.169, P=0.000\right)$, grain production efficiency $\left(\beta_{1}=0.188, P=0.000\right)$, and grain distribution efficiency $\left(\beta_{1}=0.145, P=0.000\right)$. Considering the instrumental variable and covariant, financial inclusion also significantly promotes the grain security efficiency $\left(\beta_{1}=0.127, P=0.000\right)$, grain production efficiency $\left(\beta_{1}=0.073, P=0.011\right)$, and grain distribution efficiency $\left(\beta_{1}=0.157, P=0.000\right)$. The promoting effect on the grain distribution stage is about twice that on the grain production stage. The final empirical results demonstrate that financial inclusion plays a significant role in promoting grain security efficiency, mainly reflected in grain distribution efficiency.

\subsection{Analysis of Empirical Result}

In conclusion, the econometric model based on panel regression analysis confirms that the financial inclusion of the sample countries can significantly promote the efficiency of grain security, which is mainly reflected in the promotion of grain distribution efficiency, thus confirming the research Hypothesis $\mathrm{H} 1$ and $\mathrm{H} 2$.

Financial inclusion can improve the financial demand guarantee ability of vulnerable groups in a country, provide extensive financial channels and banking office support for money use planning and wealth savings of vulnerable groups, and promote relevant groups to realize intertemporal coordination and smoothness of consumption. Financial inclusion can improve the financing and reduce the financing cost of small and micro enterprises in a country, provide a financial guarantee for business activities such as operation, investment, and innovation of small and micro enterprises, create more jobs, and promote the growth of wage levels. In conclusion, whether the improvement of financial inclusion for vulnerable groups or small and micro institutions, the extension of overall financial security channels and the expansion of financial outlets will undoubtedly contribute to the income growth of relevant vulnerable groups, and fundamentally realize the fairness and balance of income distribution in the whole society. As mentioned earlier, financial inclusion promotes the reduction of poverty and income distribution inequality, which is not only conducive to promoting the grain security capacity of low-income groups from a micro perspective, but also conducive to promoting the balance of national grain distribution from a macro perspective, to improve grain security efficiency and achieve the goal of sustainable development.

This study decomposes grain security into two links: grain production and grain distribution. The improvement of financial inclusion can not only promote grain production in the sample countries through financial support to farmers and small farms, but also promote the grain purchasing power of low-income groups through new employment and petty loans. As mentioned above, issuing production support loans to farmers has a relatively reliable expectation of grain production and sales, and the reliability of fund return is high. Therefore, ordinary financial business activities can touch such financial services. Petty loans with emergency and relief issued to low-income groups face enormous capital issuance costs and the repayment risk caused by the lack of capital flow and low credit of low-income groups. Ordinary commercial loans have conventional grain 
production support business, but the coverage of grain distribution is inadequate. It is necessary to improve financial inclusion to meet such needs. Therefore, although financial inclusion can promote grain production and contribute to grain distribution, it is mainly reflected in the support for grain distribution. Therefore, the promotion of financial inclusion to the grain security efficiency is mainly reflected in the promotion of grain distribution efficiency.

\subsection{Robustness Test}

Based on the analysis of the promotion effect of financial inclusion on grain security efficiency and its two-stage decomposition indicators, this section documents a robustness test to investigate the impact of expanding the virtual sample size and data truncation on the robustness of the analysis conclusion.

\subsubsection{Robustness Test of Bootstrap}

Firstly, the sample size in the empirical regression process of this paper is maintained at about 605, which has the disadvantage of fewer samples, which may affect the accuracy of the regression. Based on this, bootstrap is used for sampling with replacement to obtain a more gradual and effective estimator. Based on the original fixed effect regression model and 2SLS model (i.e., Equations (6)-(10)), this paper uses 2000 repeated sampling for the regression coefficient. The regression results are provided in Table 7.

Table 7. Results of the robustness test of bootstrap.

\begin{tabular}{ccccccc}
\hline \multirow{2}{*}{ Items } & \multicolumn{2}{c}{ Grain Security Efficiency } & \multicolumn{2}{c}{ Grain Production Efficiency } & \multicolumn{3}{c}{ Grain Distribution Efficiency } \\
& FE & 2SLS & FE & 2SLS & FE & 2SLS \\
\cline { 2 - 7 } & $\mathbf{( 1 )}$ & $\mathbf{( 2 )}$ & $\mathbf{( 3 )}$ & $\mathbf{( 4 )}$ & $\mathbf{( 5 )}$ & $\mathbf{( 6 )}$ \\
\hline Findex & $0.070^{* * *}(3.86)$ & $0.127^{* * *}(4.36)$ & $0.074^{* * *}(3.50)$ & $0.073^{* *}(2.21)$ & $0.009(1.20)$ & $0.157^{* * *}(5.40)$ \\
gdp & $0.001(0.04)$ & $0.031(1.13)$ & $-0.009(-0.19)$ & $0.091^{* * *}(3.61)$ & $0.008(0.68)$ & $-0.012(-0.41)$ \\
den & $0.152(1.43)$ & $0.007(0.92)$ & $0.230(1.24)$ & $0.035^{* * *}(3.83)$ & $0.060(0.97)$ & $-0.014^{*}(-1.79)$ \\
cap & $0.034(1.61)$ & $-0.018(-0.73)$ & $0.027(0.54)$ & $-0.064^{* *}$ & $0.038(1.60)$ & $0.015(0.58)$ \\
plc & $-0.005(-0.10)$ & $-0.057(-1.63)$ & $0.008(0.10)$ & $-0.044(-1.11)$ & $-0.015(-0.91)$ & $-0.066^{* *}(-2.03)$ \\
irr & $0.003(0.40)$ & $-0.024^{* * *}$ & $0.008(0.61)$ & $-0.060^{* * *}$ & $-0.003(-0.64)$ & $0.006(0.62)$ \\
ind & $-0.002(-0.18)$ & $0.001(-0.08)$ & $-0.005(-0.26)$ & $0.019(1.28)$ & $0.001(0.12)$ & $-0.012(-1.15)$ \\
N & 605 & 605 & 605 & 605 & 605 & 605 \\
R-squared & 0.1399 & - & 0.0708 & - & 0.3886 & - \\
Root MSE & - & 0.1712 & - & 0.2163 & - & 0.1710 \\
\hline
\end{tabular}

Notes: ${ }^{* * *},{ }^{* *},{ }^{*}$ stand for significant levels of $1 \%, 5 \%$ and $10 \%$ respectively, and the values in brackets are $t$-values.

It can be found in Table 7 that the regression results are robust, and the factors with the fewer samples will not affect the parameter estimation results. Specifically, after 2000 repeated sampling, financial inclusion also significantly promotes the grain security efficiency when considering the instrumental variables and covariant $\left(\beta_{1}=0.127, P=0.000\right)$, grain production efficiency $\left(\beta_{1}=0.073, P=0.027\right)$, and grain distribution efficiency $\left(\beta_{1}=0.157, P=0.000\right)$. The promotion effect on the grain distribution stage is still about twice that on the grain production stage.

\subsubsection{Robustness Test of Truncating}

As the dependent variable, grain security efficiency and its two-stage decomposition in indicators have a small amount of "full efficiency value", with an efficiency value of 1 , which can be regarded as abnormal extreme values; a certain degree of extreme values in the low efficiency value and level of financial inclusion also exist. The number of samples that are used in the regression may be greater than 557 because the extreme samples that are truncated may have repetitions $(605-12 \times 4)$. The censored data are regressed based on the original fixed effect regression model and 2SLS model (i.e., Equations (6)-(10)). The regression results are provided in Table 8. 
Table 8. Results of the robustness test of truncating.

\begin{tabular}{|c|c|c|c|c|c|c|}
\hline \multirow{3}{*}{ Items } & \multicolumn{2}{|c|}{ Grain Security Efficiency } & \multicolumn{2}{|c|}{ Grain Production Efficiency } & \multicolumn{2}{|c|}{ Grain Distribution Efficiency } \\
\hline & FE & 2SLS & FE & 2SLS & FE & 2SLS \\
\hline & (1) & (2) & (3) & (4) & (5) & (6) \\
\hline Findex & $0.020(1.23)$ & $0.106^{* * *}(5.64)$ & $0.054(1.60)$ & $0.057^{* *}(2.28)$ & $0.007(0.77)$ & $0.118^{* * *}(6.24)$ \\
\hline gdp & $0.019(1.19)$ & $0.046^{* *}(2.44)$ & $0.025(0.79)$ & $0.055^{* * *}(2.74)$ & $0.006(0.76)$ & $0.030 *(1.70)$ \\
\hline den & $0.012(0.13)$ & $0.011 *(1.95)$ & $0.018(0.10)$ & $0.027^{* * *}(3.34)$ & $0.074(1.54)$ & $-0.006(-1.09)$ \\
\hline cap & $0.021(1.12)$ & $-0.028(-1.47)$ & $-0.015(-0.40)$ & $-0.021(-1.04)$ & $0.047^{* * *}(4.67)$ & $-0.019(-1.11)$ \\
\hline plc & $\begin{array}{l}-0.007^{* *} \\
(-2.06)\end{array}$ & $\begin{array}{c}-0.056^{* * *} \\
(-7.53)\end{array}$ & $0.001(0.22)$ & $\begin{array}{c}-0.028^{* * *} \\
(-3.70)\end{array}$ & $\begin{array}{c}-0.014^{* * *} \\
(-8.26)\end{array}$ & $\begin{array}{c}-0.069^{* * *} \\
(-7.35)\end{array}$ \\
\hline irr & $0.006(0.72)$ & $\begin{array}{c}-0.028^{* * *} \\
(-4.22)\end{array}$ & $0.015(0.91)$ & $\begin{array}{c}-0.046^{* * *} \\
(-6.03)\end{array}$ & $-0.003(-0.70)$ & $-0.007(-0.95)$ \\
\hline ind & $-0.008(-0.95)$ & $0.000(0.05)$ & $-0.016(-0.96)$ & $-0.013(-1.33)$ & $-0.001(-0.24)$ & $-0.001(-0.22)$ \\
\hline $\mathrm{N}$ & 563 & 563 & 557 & 557 & 570 & 570 \\
\hline R-squared & 0.2388 & - & 0.0662 & - & 0.4390 & - \\
\hline Root MSE & - & 0.1308 & - & 0.1903 & - & 0.1174 \\
\hline
\end{tabular}

Notes: ${ }^{* * *}, * *,{ }^{*}$ stand for significant levels of $1 \%, 5 \%$ and $10 \%$ respectively, and the values in brackets are $t$-values.

It can be found in Table 8 that the regression results are still robust, and the interference of extreme values will not affect the parameter estimation results. Specifically, after excluding the extreme value, considering the instrumental variables and covariant, financial inclusion also significantly promotes the grain security efficiency $\left(\beta_{1}=0.106, P=0.000\right)$, grain production efficiency $\left(\beta_{1}=0.057, P=0.023\right)$, and grain distribution efficiency $\left(\beta_{1}=0.118, P=0.000\right)$. The promoting effect on the grain distribution stage is about twice that on the grain production stage.

\section{Additional Analysis}

The above empirical analysis results demonstrate that the promotion effect of financial inclusion on grain security efficiency is mainly reflected in the stage of grain distribution. Therefore, it is vital to focus on analyzing the impact mechanism of financial inclusion on grain distribution. According to the analysis logic of this paper, the improvement of financial inclusion can promote grain consumption and sustainable development by promoting income growth, improving income distribution, and improving residents' consumption. Therefore, the following will examine the impact of financial inclusion on grain distribution efficiency from the perspectives of residents' income distribution effect, residents' income growth effect, and consumption capacity upgrading effect. To further explore the mechanism of financial inclusion affecting grain distribution efficiency, this paper will conduct an empirical study through the mediating effect model, based on 2SLS.

Based on the general mediating effect model [50], following the idea of instrumental variables in this paper, model specification is as follows:

$$
\begin{gathered}
\text { Findex }_{i t}=\alpha_{0}+\alpha_{1} \text { FDI }_{i t}+\alpha_{2} X_{i t}+\sigma_{i t} \\
G d_{-} \text {eff } f_{i t}=\beta_{0}+\beta_{1} \text { Findex }_{i t}+\beta_{2} X_{i t}+\mu_{i t} \\
M_{i t}=\gamma_{0}+\gamma_{1} \text { Findex }_{i t}+\gamma_{2} X_{i t}+\varepsilon_{i t} \\
\text { Gd_eff } f_{i t}=\delta_{0}+\delta_{1} \text { Findex }_{i t}+\delta_{2} M_{i t}+\delta X_{i t}+\rho_{i t}
\end{gathered}
$$

In Equations (11)-(14), $M$ represents the mediating variable, which is the Gini coefficient (GINI) to measure the income equality of residents, the per capita gross national income (GNI) to measure the income level of residents, and the per capita household and actual government consumption (Ccon) to measure the social consumption capacity. Other variables have the same meaning as those in Equations (6)-(10). $\beta_{1}$ represents the total effect of financial inclusion on grain distribution efficiency, $\gamma_{1}$ represents the impact of financial inclusion on mediating variables, $\delta_{1}$ represents the direct effect of financial inclu- 
sion on grain distribution efficiency, and $\delta_{2}$ indicates the impact of mediating variables on grain distribution efficiency. The above parameters are the objects that need to be focused on in the empirical analysis results of this section.

\subsection{Mechanism Analysis of Income Equality Effect}

According to Equations (11)-(14), this paper uses the method of stepwise regression based on 2SLS to test the mediating role of residents' income distribution effect in the promotion effect of financial inclusiveness on grain distribution efficiency. The regression results are provided in Table 9.

Table 9. The estimation results for the mediating role of the GINI index.

\begin{tabular}{cccc}
\hline Items & Gd-eff & GINI Index & Gd-eff \\
\cline { 2 - 4 } & $\mathbf{( 1 )}$ & $\mathbf{( 2 )}$ & $\mathbf{( 3 )}$ \\
\hline Findex & $0.157^{* * *}(6.01)$ & $-0.046^{* * *}(-3.43)$ & $0.136^{* * *}(6.16)$ \\
GINI index & - & - & $-0.453^{* * *}(-6.17)$ \\
gdp & $-0.012(-0.43)$ & $-0.004(-0.36)$ & $-0.014(-0.58)$ \\
den & $-0.014^{*}(-1.87)$ & $-0.007(-1.64)$ & $-0.017^{* *}(-2.43)$ \\
cap & $0.015(0.61)$ & $0.013(1.11)$ & $0.021(0.97)$ \\
plc & $0.015^{* * *}(-6.92)$ & $0.020^{* * *}(5.42)$ & $-0.057^{* * *}(-6.53)$ \\
irr & $0.006^{* * *}(0.63)$ & $0.016^{* * *}(3.09)$ & $0.014(1.46)$ \\
ind & $-0.012(-1.22)$ & $-0.015^{* * *}(-3.21)$ & $-0.019^{* *}(-2.17)$ \\
N & Yes & Yes & Yes \\
Instrumental variable & 605 & 605 & 605 \\
Root MSE & 0.1710 & 0.0898 & 0.1562 \\
\hline Notes: $* * * * * *$ stand for significant levels of $1 \%, 5 \%$ and $10^{*} \%$ respectively, and the values in brackets are $t$-values.
\end{tabular}

By observing Table 10, it can be found that financial inclusion has significantly promoted the efficiency of grain distribution through the effect of residents' income growth. Column (1) verifies the comprehensive impact of financial inclusion on grain distribution efficiency, $\left(\beta_{1}=0.157, p=0.000\right)$, which is consistent with the benchmark 2SLS regression result; column (2) verifies the impact of financial inclusion on GINI index $\left(\gamma_{1}=-0.046, p=0.001\right)$, which means that financial inclusion inhibits GINI index, that is, financial inclusion improves the equality of residents' income distribution; the impact of the coefficient of financial inclusion on grain distribution efficiency in column (3) is $0.136(p=0.000)$, which is slightly lower than the impact of the coefficient of financial inclusion on grain distribution efficiency in column (1), which is $0.157(p=0.000)$. The impact coefficient of mediating variable on the GINI index on grain distribution efficiency is $-0.453(p=0.000)$, which means that the improvement of residents' income equality will promote the progress of grain distribution efficiency. To sum up, a fraction of the role of financial inclusion in promoting grain distribution efficiency is realized by promoting the development of residents' income equality.

\subsection{Mechanism Analysis of Income Promotion Effect}

According to Equations (11)-(14), this paper uses the method of stepwise regression based on 2SLS to test the mediating role of residents' income promotion effect in the promotion effect of financial inclusion on grain distribution efficiency. The regression results are presented in Table 10. 
Table 10. The estimation results for the mediating role of GNI.

\begin{tabular}{cccc}
\hline Items & Gd-eff & GNI & Gd-eff \\
\cline { 2 - 4 } & $\mathbf{( 1 )}$ & $\mathbf{( 2 )}$ & $\mathbf{( 3 )}$ \\
\hline Findex & $0.157^{* * *}(6.01)$ & $34.454^{* * *}(6.77)$ & $0.064^{* * *}(3.87)$ \\
GNI & - & - & $0.003^{* * *}(7.47)$ \\
gdp & $-0.012(-0.43)$ & $10.399^{*}(1.73)$ & $-0.040^{* *}(-2.22)$ \\
den & $-0.014^{*}(-1.87)$ & $-3.561^{* * *}(-2.61)$ & $-0.004(-0.85)$ \\
cap & $0.015(0.61)$ & $-12.689^{* *}(-2.52)$ & $0.049^{* * *}(2.73)$ \\
plc & $0.015^{* * *}(-6.92)$ & $-10.332^{* * *}(-7.17)$ & $-0.038^{* * *}(-4.92)$ \\
irr & $0.006^{* * *}(0.63)$ & $-2.764(-1.51)$ & $0.014^{*}(1.76)$ \\
ind & $-0.012(-1.22)$ & $-1.989(-0.92)$ & $-0.006(-1.25)$ \\
Instrumental variable & Yes & Yes & Yes \\
N & 605 & 605 & 605 \\
Root MSE & 0.1710 & 30.679 & 0.1309 \\
\hline
\end{tabular}

Notes: ${ }^{* * *}, * *,{ }^{*}$ stand for significant levels of $1 \%, 5 \%$ and $10 \%$ respectively, and the values in brackets are $t$-values

It can be found from Table 10 that financial inclusion has significantly promoted the efficiency of grain distribution through residents' income promotion. Column (1) is consistent with the benchmark 2SLS regression results; column (2) verifies the impact of financial inclusion on GNI $\left(\gamma_{1}=34.454, p=0.000\right)$, which means that financial inclusion improves GNI, that is, promotes the income level of residents; the influence coefficient of financial inclusion on grain distribution efficiency in column (3) is $0.064(p=0.000)$, which is lower than the influence coefficient of financial inclusion on grain distribution efficiency in column (1), which is $0.157(p=0.000)$. The influence coefficient of the mediating variable GNI on grain distribution efficiency is $0.003(p=0.000)$, which means that the improvement of residents' income level will lead to the progress of grain distribution efficiency. In conclusion, the role of financial inclusion in promoting grain distribution efficiency is largely realized by promoting residents' income levels.

\subsection{Mechanism Analysis of Consumption Promotion Effect}

According to Equations (11)-(14), this paper uses the method of stepwise regression based on 2SLS to test the mediating role of the upgrading effect of consumption capacity in the promotion effect of financial inclusion on grain distribution efficiency. The regression results are presented in Table 11.

Table 11. The estimation results for the mediating role of Ccon.

\begin{tabular}{cccc}
\hline \multirow{2}{*}{ Items } & Gd-eff & Ccon & Gd-eff \\
\cline { 2 - 4 } & $\mathbf{( 1 )}$ & $\mathbf{( 2 )}$ & $\mathbf{( 3 )}$ \\
\hline Findex & $0.157^{* * *}(6.01)$ & $22.026^{* * *}(6.72)$ & $-0.024(-0.68)$ \\
Ccon & - & - & $0.008^{* * *}(13.30)$ \\
gdp & $-0.012^{*}(-0.43)$ & $3.197(0.80)$ & $-0.038^{* *}(-2.48)$ \\
den & $-0.014^{*}(-1.87)$ & $-2.601^{* * *}(-3.01)$ & $0.007(1.59)$ \\
cap & $0.015(0.61)$ & $-4.222(-1.27)$ & $0.050^{* * *}(3.29)$ \\
plc & $0.015^{* * *}(-6.92)$ & $-6.977^{* * *}(-7.32)$ & $-0.009(-1.55)$ \\
irr & $0.006^{* * *}(0.63)$ & $-0.404(-0.34)$ & $0.010(1.48)$ \\
ind & $-0.012(-1.22)$ & $-1.883(-1.36)$ & $0.004(0.80)$ \\
Instrumental variable & Yes & Yes & Yes \\
$\mathrm{N}$ & 605 & 605 & 605 \\
Root MSE & 0.1710 & 19.898 & 0.1195 \\
\hline
\end{tabular}

It can be found from Table 11 that financial inclusion has significantly promoted grain distribution efficiency through the upgrading of consumption capacity. Column (1) is consistent with the benchmark 2SLS regression results; column (2) verifies the impact of financial inclusion on Ccon $\left(\gamma_{1}=22.026, p=0.000\right)$, which means that financial inclusion 
improves Ccon, that is, it promotes the actual consumption of per capita household and government; the impact coefficient of financial inclusion on grain distribution efficiency in column (3) is -0.024 and not significant, which is lower than the impact coefficient of financial inclusion on grain distribution efficiency in column (1) of $0.157(p=0.000)$; the influence coefficient of the mediating variable Ccon on the grain distribution efficiency is $0.008,(p=0.000)$, which means that the improvement of the actual consumption level of families and governments will lead to the progress of grain distribution efficiency. In conclusion, the role of financial inclusion in promoting grain distribution efficiency can be achieved by promoting social consumption capacity.

\subsection{Analysis of Mechanism}

It can be observed that the mediating effect model based on 2SLS confirms the mechanism of financial inclusive promotion to improve the efficiency of grain distribution by promoting residents' income growth, income distribution, and consumption, thus supporting the research Hypothesis H3. Grain security is divided into production and distribution. The promotion of financial inclusion to grain security capacity is mainly reflected in the distribution. The improvement of grain distribution efficiency is the key basis for ensuring grain supply, especially for low-income groups, and can promote the realization of "sustainable development goal 2".

It should be noted that the subject of social consumption capacity in this paper includes both residents and the government. Household consumption is highly related to the growth and distribution of residents' income. The degree of government tax abundance and fiscal expenditure is also closely related to economic development and residents' income level. A large part of government consumption is used for transfer payment projects to promote the fair distribution of residents' income. There is a close relationship between income growth, income distribution, and consumption improvement. The improvement of income growth and income distribution balance is the supporting basis of consumption promotion. Therefore, there is a close correlation between financial inclusion promoting income growth, promoting income distribution, and promoting consumption. Improving social consumption capacity overlaps with the effect of residents' income growth and improving distribution level, to a certain extent.

\section{Conclusions and Implications}

This study measures the financial inclusion level of countries according to the Financial Access Survey implemented by the IMF. The grain security capacity of the sample countries is measured from production and distribution. On this basis, this paper analyzes the impact of financial inclusion on the improvement of grain security capacity of sample countries, to investigate the role of financial inclusion in achieving the "sustainable development goal 2" of the United Nations. From the empirical results and analysis, several important findings and implications can be summarized.

Firstly, the study found that financial inclusion has a significant role in improving the grain security capacity of the sample countries. The improvement of financial inclusiveness not only helps to improve residents' income, but also promotes the balance of income distribution. From the micro individual perspective, financial inclusion can significantly improve the ability of low-income groups to obtain financial services and improve their income level through lower transaction costs, faster access speed, and wider access. The improvement of income level is of great benefit to ensuring the food purchasing ability of low-income groups and families. From a macro perspective, the improvement of the income level of low-income families can achieve twice the result with half the effort to promote the overall social balance, which can achieve the effect of improving the food security capacity of low-income groups and promoting the overall food security capacity of the people. Article 2 of the United Nations' sustainable development goals is to eradicate hunger, achieve grain security, improve nutrition, and promote sustainable agriculture. Therefore, this study also confirms the role of financial inclusion in achieving sustainable development 
goal 2. It is worth noting that the two-stage grain security efficiency indicators set in this study are mainly composed of indicators reflecting the health status of the population, such as the nutrition rate of the total population, the rate of children underweight, the prevalence of child wasting, the rate of child stunting, and the rate of child mortality. Relevant indicators reflect the overall population and the health status of the youth population in the sample countries, which is reflected in the sustainability of population development, which further illustrates the key role of financial inclusion in the sustainable development of population and society.

Secondly, it is found that financial inclusion has a more significant impact on grain distribution efficiency. This study is divided into two links, grain production and grain distribution, to investigate the impact of financial inclusion on grain distribution efficiency. Financial inclusion will promote grain security in both production and distribution, but it is mainly reflected in the promotion of grain distribution. This study believes that the biggest advantage of improving financial inclusiveness relative to expanding the scale of traditional finance is to overcome some disadvantages of traditional finance, to realize some fundamental changes. Traditional financial institutions and financial activities can provide appropriate support for grain production for the purpose of profit, but almost inevitably omit the ability of low-income families with fragile capital chains and a lack of mortgage assets to seek financial support to overcome short-term financial difficulties and ensure food supply. The improvement of financial inclusiveness has greatly overcome the corresponding disadvantages. Low-income families in financial difficulties can obtain temporary support by relying on the wide coverage of financial inclusiveness. Individuals who lack investment principals can obtain reliable financing support by the improvement of financial inclusiveness, and may obtain a stable source of income and food purchasing ability. This study has important reference value for promoting the improvement of grain security capacity and realizing the sustainable development of grain security by improving financial inclusion; that is, both primary distribution and redistribution contribute to the sustainable development of grain security in the sample countries, but more attention should be paid to improving the efficiency of grain security by expanding the coverage and depth of financial services.

Thirdly, it is found that financial inclusion promotion can facilitate grain distribution through mediating variables such as income and consumption. By introducing the mediating effect model of 2SLS, this paper further confirms the mechanism of financial inclusion to improve the efficiency of grain distribution by promoting residents' income growth, income distribution, and consumption. Therefore, unblocking financial inclusion to improve food security capacity should focus on increasing income, promoting income distribution, and stabilizing consumption expectations.

Admittedly, there are several deficiencies in this paper. (1) Although the impact of financial inclusion on food security efficiency provides guidance for sustainable development policies, this conclusion depends on historical data and mathematical reasoning, and lacks in-depth economic theoretical analysis. This disadvantage may limit the long-term effectiveness of research results in the future, but only reflect the facts of the past. In future research, we should build a more universal economic theoretical model to verify the effectiveness and prediction ability of the results of this paper. (2) It should be pointed out that most of the control variables used in the empirical process of this paper reflect a country's economic development and have insufficient correlation with food security, which is limited by the existing data. It is not easy to collect food related data from more than 100 sample countries. In fact, most of the data that can reflect a country's food development have been included in the constituent indicators of food security efficiency. (3) The traditional fixed effect panel model has two disadvantages. The first disadvantage is that it ignores the impact of surrounding countries on variables in the spatial dimension; that is, it ignores the impact of financial inclusiveness and food security efficiency of surrounding countries on local financial inclusiveness and food security efficiency. To solve this problem, previous studies mainly used traditional spatial econometric models such as the spatial 
lag model (SLM), spatial error model (SEM), and spatial Dobbin model (SDM), but did not analyze the spatial interaction between core variables. Therefore, we will establish spatial simultaneous equations to comprehensively analyze the relationship between core variables in the future. The second disadvantage is that the possible correlation between endogenous variables and random disturbance terms is not considered. We consider using generalized space three-stage least squares (gs3sls) for analysis in the future, which is a complete information estimation method of simultaneous equation model.

Overall, achieving the 17 key goals in the 2030 agenda for sustainable development is an ideal vision for promoting sustainable development for all humanity. This study confirms the role of financial inclusion in achieving sustainable development goal 2. It is conceivable that the lagging financial development level and the absence of financial inclusion in some countries and regions will seriously affect the grain security and health status of the corresponding vulnerable groups. China's valuable experience in achieving sustainable development and grain security could be used to rapidly improve the access of low-income groups to formal financial channels, through technical means such as digital finance, and policy tools such as targeted poverty alleviation. Developing countries with backward financial development levels should take advantage of the favorable opportunity of the rapid development of digital financial technologies such as big data and cloud computing to effectively improve the level of financial inclusion and financial development, and ensure the financial service needs of residents, especially low-income groups, to achieve low-level but core sustainable development goals such as eradicating hunger and poverty. The international community and developed countries should give strong support in "unprofitable" areas such as improving the financial inclusion of developing countries, effectively eradicating hunger and poverty worldwide. Although the commercial value of this is not high, it is in line with the common values of all humanity, which is also the value of this study.

Author Contributions: Conceptualization, S.J.; data curation, Y.Q. and C.Y.; formal analysis, Y.Q. and C.Y.; funding acquisition, S.J.; investigation, S.J.; methodology, Y.Q. and C.Y.; project administration, S.J.; resources, C.Y.; software, C.Y.; supervision, S.J.; validation, S.J. and Y.Q.; visualization, S.J. and Y.Q.; writing—original draft, S.J. and C.Y.; writing—review \& editing, S.J., Y.Q. and C.Y. All authors have read and agreed to the published version of the manuscript.

Funding: This research was funded by the National Social Science Fund of China, grant number 21CTJ013.

Institutional Review Board Statement: Not applicable.

Informed Consent Statement: Not applicable.

Data Availability Statement: The data presented in this study are available on request from the author.

Conflicts of Interest: The authors declare no conflict of interest.

\section{References}

1. Valentini, R.; Sievenpiper, J.; Antonelli, M.; Dembska, K. Achieving the Sustainable Development Goals Through Sustainable Food Systems; Springer International Publishing: Berlin/Heidelberg, Germany, 2019.

2. Sarma, M.; Pais, J. Financial inclusion and development. J. Int. Dev. 2011, 23, 613-628. [CrossRef]

3. Beck, T.; Levine, R. Stock Markets, Banks, and Growth: Panel Evidence. J. Bank. Financ. 2002, 28, 423-442. [CrossRef]

4. Galor, O.; Moav, O. From Physical to Human Capital Accumulation: Inequality in the Process of Development. Rev. Econ. Stud. 2004, 71, 1001-1026. [CrossRef]

5. Levine, R.; Beck, T.; Demirguc-Kunt, A. Finance, Inequality and the Poor. J. Econ. Growth 2007, 12, $27-49$.

6. Claessens, S.; Perotti, E. Finance and inequality: Channels and evidence. J. Comp. Econ. 2007, 35, 748-773. [CrossRef]

7. Seven, U.; Coskun, Y. Does financial development reduce income inequality and poverty? Evidence from emerging countries. Emerg. Mark. Rev. 2016, 26, 34-63. [CrossRef]

8. Greenwood, J.; Jovanovic, B. Financial Development, Growth, and the Distribution of Income. J. Political Econ. 1990, 98, 1076-1107. [CrossRef]

9. Liu, G.; Huang, Y.Y.; Huang, Z.H. Determinants and Mechanisms of Digital Financial Inclusion Development: Based on Urban-Rural Differences. Agronomy 2021, 11, 1833. [CrossRef] 
10. Conroy, J. APEC and financial exclusion: Missed opportunities for collective action? Asia-Pac. Dev. J. 2005, 12, 53-79. [CrossRef]

11. Park, C.-Y.; Mercado, J.R. Financial Inclusion, Poverty, and Income Inequality in Developing Asia; World Scientific Publishing Co. Pte Ltd.: Singapore, 2015.

12. Burgess, R.; Pande, R. Do Rural Banks Matter? Evidence from the Indian Social Banking Experiment. Am. Econ. Rev. 2005, 95, 780-795. [CrossRef]

13. Brune, L.; Gine, X.; Goldberg, J.; Yang, D. Commitments to Save: A Field Experiment in Rural Malawi. World Bank Policy Res. Work. Pap. 2011.

14. Allen, F.; Carletti, E.; Cull, R.; Qian, J.; Senbet, L.; Valenzuela, P. Resolving the African Financial Development Gap: Cross-Country Comparisons and a Within-Country Study of Kenya; University of Chicago Press: Chicago, IL, USA, 2012.

15. Erlando, A.; Riyanto, F.; Masakazu, S. Financial inclusion, economic growth, and poverty alleviation: Evidence from eastern Indonesia. Heliyon 2020, 6, e05235. [CrossRef]

16. Bank, W. Global Financial Development Report 2014: Financial Inclusion. World Bank Publ. 2014, 4, 121-135.

17. Dhrifi, A. Financial Development and the "Growth-Inequality-Poverty" Triangle. J. Knowl. Econ. 2015, 6, 1163-1176. [CrossRef]

18. Neaime, S.; Gaysset, I. Financial inclusion and stability in MENA: Evidence from poverty and inequality. Financ. Res. Lett. 2018 24, 230-237. [CrossRef]

19. Li, Y.; Li, W. Do fodder import and credit loans lead to climate resiliency in the pastoral social-ecological system of Inner Mongolia? Ecol. Soc. 2021, 26, 27. [CrossRef]

20. Ahearn, A. Pastoralist Livelihoods in Asian Drylands: Environment, Governance and Risk; The White Horse Press: Cambridgeshire, UK, 2017.

21. Zhang, Z.; Wu, J. How do market-based rangeland institutional reforms affect herders engagement with credit loans within the pastoral regions of the Tibetan Plateau? J. Rural. Stud. 2020, 73, 1-9.

22. Wood, D.C. Introduction: Individual and Social Adaptations to Vulnerability. In Individual and Social Adaptations to Human Vulnerability; Emerald Publishing Limited: Bingley, UK, 2018; Volume 38, pp. 1-5.

23. Taylor, M. 'Freedom from poverty is not for free': Rural development and the microfinance crisis in Andhra Pradesh, India. J. Agrar. Chang. 2011, 11, 484-504. [CrossRef]

24. Karen, E.; Alberto, L.; Juan-Pablo, R. Investigating the Impact of Access to Financial Services on Household Investment. In Financial Inclusion in Kenya; FSD Kenya: Nairobi, Kenya, 2011.

25. Stiglitz, J.E. The Role of the State in Financial-Markets. World Bank Econ. Rev. 1993, 7, 19-52. [CrossRef]

26. Boukhatem, J. Assessing the direct effect of financial development on poverty reduction in a panel of low- and middle-income countries. Res. Int. Bus. Financ. 2016, 37, 214-230. [CrossRef]

27. Foyer, C.H.; Lam, H.-M.; Nguyen, H.T.; Siddique, K.H.M.; Varshney, R.K.; Colmer, T.D.; Cowling, W.; Bramley, H.; Mori, T.A.; Hodgson, J.M.; et al. Neglecting legumes has compromised human health and sustainable food production. Nat. Plants 2016, 2, 16112. [CrossRef] [PubMed]

28. Xu, J.; Henry, A.; Sreenivasulu, N. Rice yield formation under high day and night temperatures-A prerequisite to ensure future food security. Plant Cell Environ. 2020, 43, 1595-1608. [CrossRef]

29. Kumar, D.; Kalita, P. Reducing Postharvest Losses during Storage of Grain Crops to Strengthen Food Security in Developing Countries. Foods 2017, 6, 8. [CrossRef] [PubMed]

30. Ge, D.; Long, H.; Zhang, Y.; Ma, L.; Li, T. Farmland transition and its influences on grain production in China. Land Use Policy 2018, 70, 94-105. [CrossRef]

31. Amidzic, G.; Massara, A.; Mialou, A. Assessing Countries' Financial Inclusion Standing-A New Composite Index; IMF Working Papers; International Monetary Fund: Washington, DC, USA, 2014; Volume 14. [CrossRef]

32. Montgomery, H.; Weiss, J. Modalities of microfinance delivery in Asia and Latin America: Lessons for China. China World Econ. 2006, 14, 30-43. [CrossRef]

33. Zhuang, J.; Gunatilake, H.M.; Niimi, Y.; Khan, M.E.; Jiang, Y.; Hasan, R.; Khor, N.; Martin, A.L.; Bracey, P.; Huang, B. Financial sector development, economic growth, and poverty reduction: A literature review. Asian Dev. Bank Econ. Work. Pap. Ser. $2009,173$. [CrossRef]

34. Naz, M.; Iftikhar, S.F.; Fatima, A. Formal financial penetration and households' welfare in Pakistan. Int. J. Financ. Eng. 2020, 7, 2050041. [CrossRef]

35. Dahiya, S.; Kumar, M. Linkage between financial inclusion and economic growth: An empirical study of the emerging Indian economy. Vision 2020, 24, 184-193. [CrossRef]

36. Ratnawati, K. The impact of financial inclusion on economic growth, poverty, income inequality, and financial stability in Asia. $J$. Asian Financ. Econ. Bus. 2020, 7, 73-85. [CrossRef]

37. Naz, M.; Iftikhar, S.F.; Fatima, A. Does financial inclusiveness matter for the formal financial inflows? Evidence from Pakistan. Quant. Financ. Econ. 2020, 4, 19-35. [CrossRef]

38. Li, Z.; Ao, Z.; Mo, B. Revisiting the Valuable Roles of Global Financial Assets for International Stock Markets: Quantile Coherence and Causality-in-Quantiles Approaches. Mathematics 2021, 9, 1750. [CrossRef]

39. Matei, I. Is financial development good for economic growth? Empirical insights from emerging European countries. Quant. Financ. Econ. 2020, 4, 653-678. [CrossRef] 
40. Wang, S.; Yang, C.; Li, Z. Spatio-Temporal Evolution Characteristics and Spatial Interaction Spillover Effects of New-Urbanization and Green Land Utilization Efficiency. Land 2021, 10, 1105. [CrossRef]

41. Yao, Y.; Hu, D.; Yang, C.; Tan, Y. The impact and mechanism of fintech on green total factor productivity. Green Finance 2021, 3, 198-221. [CrossRef]

42. Su, Y.; Li, Z.; Yang, C. Spatial Interaction Spillover Effects between Digital Financial Technology and Urban Ecological Efficiency in China: An Empirical Study Based on Spatial Simultaneous Equations. Int. J. Environ. Res. Public Health 2021, 18, 8535. [CrossRef]

43. Yang, C.; Li, T.; Albitar, K. Does Energy Efficiency Affect Ambient PM2.5? The Moderating Role of Energy Investment. Front. Environ. Sci. 2021, 9, 707751. [CrossRef]

44. Demirtas, Y.E.; Kececi, N.F. The efficiency of private pension companies using dynamic data envelopment analysis. Quant. Financ. Econ. 2020, 4, 204-219. [CrossRef]

45. Charnes, A.W.; Cooper, W.W.; Rhodes, E. Measuring The Efficiency of Decision Making Units. Eur. J. Oper. Res. 1979, 2, 429-444. [CrossRef]

46. Tavana, M.; Mirzagoltabar, H.; Mirhedayatian, S.M.; Saen, R.F.; Azadi, M. A new network epsilon-based DEA model for supply chain performance evaluation. Comput. Ind. Eng. 2013, 66, 501-513. [CrossRef]

47. Tone, K.; Tsutsui, M. Network DEA: A slacks-based measure approach. Eur. J. Oper. Res. 2009, 197, 243-252. [CrossRef]

48. Li, Z.; Zou, F.; Tan, Y.; Zhu, J. Does Financial Excess Support Land Urbanization-An Empirical Study of Cities in China. Land 2021, 10, 635. [CrossRef]

49. Li, T.; Ma, J.; Mo, B. Does the Land Market Have an Impact on Green Total Factor Productivity? A Case Study on China. Land 2021, 10, 595. [CrossRef]

50. Hayes, A. Beyond Baron and Kenny: Statistical Mediation Analysis in the New Millennium. Commun. Monogr. 2009, 76, 408-420. [CrossRef] 